\title{
Designing playful interactions for social interaction and physical play
}

\author{
Tilde Bekker · Janienke Sturm $\cdot$ Berry Eggen
}

Received: 6 March 2009/ Accepted: 16 July 2009/Published online: 17 December 2009

(c) The Author(s) 2009. This article is published with open access at Springerlink.com

\begin{abstract}
This paper describes three design values that we apply for designing playful interactions. Interactive play objects can stimulate social interaction and physical play by providing motivating feedback to players' behavior; they can allow players to create their own game goals and rules in an open-ended play context and support social player interaction patterns. This design approach is illustrated by six design cases in which our assumptions were examined in various play contexts. The results show that the application of these design values can lead to rich and appealing innovative play concepts. Players can create a wide range of (physical) games using open-ended play objects, and properties of the play objects, such as being personal or shared, influence the type of social interaction.
\end{abstract}

Keywords Intelligent play objects - Social interaction Physical activity $\cdot$ Creativity $\cdot$ Emergent behavior

\section{Introduction}

A large part of children's lives is spent playing. By playing children practice skills and explore imaginary worlds [1].

\author{
T. Bekker $(\bowtie) \cdot$ J. Sturm $\cdot$ B. Eggen \\ Industrial Design Department, \\ Eindhoven University of Technology, \\ P.O. Box 513, Den Dolech 2, 5600 MB Eindhoven, \\ The Netherlands \\ e-mail: m.m.bekker@tue.nl \\ J. Sturm \\ e-mail: j.sturm@tue.nl \\ B. Eggen \\ e-mail: j.h.eggen@tue.nl
}

In the past, children's play used to take place outdoors and had a highly social and physical nature. Nowadays, children spend increasing amounts of their time playing computer games and watching television, and they tend not to meet the recommended norms for physical activity [24, 34]. The lack of physical activity may not only result in health risks but may also have negative consequences for children's social skills and social life, since a lot of communication takes place in the virtual rather than in the real world. In our research, we examine how (outdoor) physical play can be enriched in a way that appeals to children, thus creating attractive play alternatives to computers and television.

We explore how interactive play objects can provide novel play opportunities by designing interactive play objects that make use of digital technology such as sensors, actuators, and computing power to create intelligent system behavior. The play objects can measure the user's movements and use this information to provide motivating feedback or to adapt the games to the children's skill level. We create playful solutions that stimulate social interaction between children through physical play. In our research, we have examined how design decisions influence players' behaviors. So far, we have designed various playful interaction concepts for sport contexts, for intelligent playgrounds and for indoor contexts $[5,6,8,17,22$, 41, 42].

In this paper, we present our design values and their theoretical underpinnings, describe the main assumptions we have been investigating and illustrate our work with a variety of design cases. The emphasis of the paper is on presenting our vision on designing playful interactions developed over the years, as opposed to describing single case studies in detail as was done in previous papers $[5,6$, $8,9,17,22,40]$. The strength of the work presented lies in 
iteratively developing a design philosophy and validating our assumptions by creating working prototypes for various contexts of use.

\section{Related work}

Our work on social and physical games is closely related to research on other types of games. Exertion interfaces or exergames-interfaces that require some form of exercise or exertion-have been studied in several research projects, for example Ishii et al. [21] have designed an enhanced version of ping pong, called PingPongPlus. Mueller et al. [28] have designed various applications to play sports at a distance, and Rogers and Muller [37] have designed an adventure game for children which requires physical interaction. Apart from these exertion interfaces, our work has links with pervasive games or social games. Pervasive (or location-aware or augmented reality) games bring the gaming experience from the world of computers and the internet into the real-world environment of the game player, by wireless and location-based technologies [27]. An example of a pervasive game for adults is Can You See Me Now, which is played both online in a virtual city and on the streets of an actual city [10]. An example of a game specifically designed for children is the Ambient Wood project, which is a pervasive educational game. In this game, children could explore a technology-enhanced wood [36]. A new genre of pervasive games is Head Up Games: technology enhanced games that do not require screenbased interaction and therefore allow for rich social interaction [39]. Camelot is an example of such an outdoor game in which children collaboratively create physical castles (see also the paper by Soute and Markopoulos in this special issue).

Various other games focus on specifically on social interaction between children. The mixed-reality table top game aMAZEd [2] is a maze game where teams of children have to reach various locations in the maze to get to the next phase of the game. Game elements such as bluffing and competition and psycho-physiological feedback were used to encourage social interaction. Age Invaders [12] is an inter-generational mixed-reality game in which children, parents, and their grand-parents play a socio-physical game. Active players move about on an electronic game board and can trigger rockets and bombs, while online players can help the active players.

Our approach differs from those mentioned above in the sense that we combine aspects from various areas. We create solutions where multiple players can be both physically and socially active: through social interaction they negotiate about game goals and rules to adapt the games that they play. Furthermore, we focus on co-located solutions where objects provide feedback without using computer screens.

\section{Research through design approach}

We follow a research through design approach which means that we generate scientific knowledge through cycles of creating and evaluating structurally varied, experiential prototypes. Theoretical insights that are acquired in this way and/or scientific knowledge that is available in literature are incorporated into the design variations, and it is empirically tested how the variations influence product experience. In this way, we iteratively develop an understanding of how design decisions influence players' behavior, using theories about child development, human behavior, sport psychology, emergent behavior and game design. Throughout our research we have created various play concepts focusing on stimulating physical play, such as a physical prop controlled by children's own physical movements and enhanced sports objects for football, skating, basketball, and tennis [5]. We have also created various design solutions that stimulate social interaction and creativity, such as abstract, responsive play objects that react to players' behavior. We have done research with objects intended for children as well as for adults, with objects that were context-independent or to enhance existing activities such as skating, and objects that were completely novel or extensions to a commercially available product.

\section{Design values}

The focus of our research is on stimulating physical activity and social interaction [7]. We have identified a set of design values that supports our vision. The first design value is to provide motivating feedback to players' behavior. The second design value is based on creating opportunities for players to define their own game goals and rules. The third design value focuses on creating social player-interaction patterns, by designing various opportunities for players to collaborate and compete with each other using interactive play objects. We will explain the theories related to each of our design values and then describe the related design research.

\subsection{Design case overview}

In this section, we will present six design cases (see the acknowledgements for the designers and students, who collaborated in the cases) to illustrate how the three design values described above have influenced our work. Many of the design cases address more than one of the design values; these are presented under the heading where they had most impact (see Table 1). 
Table 1 Overview of the design cases and the design values they address

\begin{tabular}{|c|c|c|c|c|}
\hline \multicolumn{2}{|c|}{ Project name } & \multirow{2}{*}{$\begin{array}{l}\text { Design value 1: } \\
\text { Motivating } \\
\text { feedback }\end{array}$} & \multirow{2}{*}{$\begin{array}{l}\text { Design value 2: } \\
\text { Open-ended } \\
\text { play }\end{array}$} & \multirow{2}{*}{$\begin{array}{l}\text { Design value 3: } \\
\text { Social interaction } \\
\text { patterns }\end{array}$} \\
\hline 1. & $\begin{array}{l}\text { Battle Bots: battle-tank toys that can be controlled through } \\
\text { body movements }\end{array}$ & & & \\
\hline 2. & $\begin{array}{l}\text { Feedball: a ball that senses the precision of a pass and } \\
\text { provides light feedback }\end{array}$ & $X$ & & \\
\hline 3. & $\begin{array}{l}\text { Ledtube: an object that detects shaking or rolling and } \\
\text { changes colored light feedback }\end{array}$ & $\mathrm{X}$ & $X$ & \\
\hline 4. & $\begin{array}{l}\text { ColorFlare: an object that responds to player movements } \\
\text { and can communicate its uni-modal state to other similar objects }\end{array}$ & $X$ & $X$ & $X$ \\
\hline 5. & $\begin{array}{l}\text { MultiModalMixer: objects that provide multi-modal feedback } \\
\text { to player movements and can communicate its state to other similar objects }\end{array}$ & $\mathrm{X}$ & $X$ & $\mathrm{X}$ \\
\hline 6. & Swinxsbee: a shared object to be used with an outdoor game console & $\mathrm{X}$ & & $X$ \\
\hline
\end{tabular}

Italicised cells indicate that the design case is first presented under the heading of that design value

\subsection{Motivating feedback}

Our first design value concerns providing immediate motivating feedback to players' physical activity. Physical activity can be broken down into various components, such as strength, endurance, speed, balance, and coordination [19, 32]. Rather than addressing all these components explicitly in our studies, we design concepts that motivate children to participate in physical games, and thus contribute to their meeting the general physical activity norm, which states that children should be physically active for 60 min every day (Dutch Norm [23] and the American Norm [13]). These play concepts are inspired by theories and models about human behavior and behavior change. The self efficacy theory [4], for example, describes that people's behavior is influenced by beliefs about their being able to do certain activities and their outcome expectations. Such theories provide ideas about which behaviors can be influenced through the use of a specific product. For example, providing positive experiences and motivating feedback can contribute to children's self efficacy and thus to their intention to play a sport. In the area of persuasion theories, Fogg [15] describes how technology can be used to influence people's behavior, e.g., as a tool to make keeping track of certain behavior easier. Specifically in the context of sport-like activities, these ideas can be related to theories about sport psychology. IJsselsteijn et al. [20] describe how persuasive technology may be a powerful tool to help people adapt their behavior by presenting relevant and actionable information at the right time.

Playing sports can help children develop many different skills. Apart from working on their physical development, e.g. strength, stamina, and motor skills children also develop cognitive skills (e.g. learning about rules and strategies) and social skills (e.g. negotiation and turn- taking) [19]. Children practice sports because they think it is fun to do, they enjoy making friends, want to become fit and develop new skills. However, lack of fun, lack of excitement, lack of exercise and fitness and insufficient challenges are reasons for children to stop playing a sport [45]. Enhancing children's sport experiences, for example by providing feedback to appealing challenges can possibly increase children's motivation to play sports and sportslike games. Our initial projects examined how to enhance children's sport experiences by embedding sensor and actuator combinations in intelligent play objects.

We first examined whether children enjoy receiving feedback about their own behavior in a game-like context, and whether interesting challenges could be created around their own behavior. Subsequently, we applied this approach in different physical play contexts, related to sports such as football, skating, and basketball [8]; we describe one example from a football context.

\subsubsection{Design case 1: Battle Bots}

One of our first explorations of designing for physical play was the Battle Bots project [5]. The main goal of this project was to develop a game for 8-0-year-olds in which body movements of children would be used to control a physical prop for outdoor play. An iterative design process resulted in the Battle Bots concept, which is a physical game in which children's movements are used to remotely control battle-tank toys (see Fig. 1).

The Battle Bots can drive around and shoot at other Battle Bots using infrared communication. The Battle Bots support activities, such as hunting, seeking, hiding, fighting, aiming, and shooting, which appeal to 8-10-year-old children [1]. The Battle Bot is controlled by the child's movements: a vest and a glove containing motion sensors 


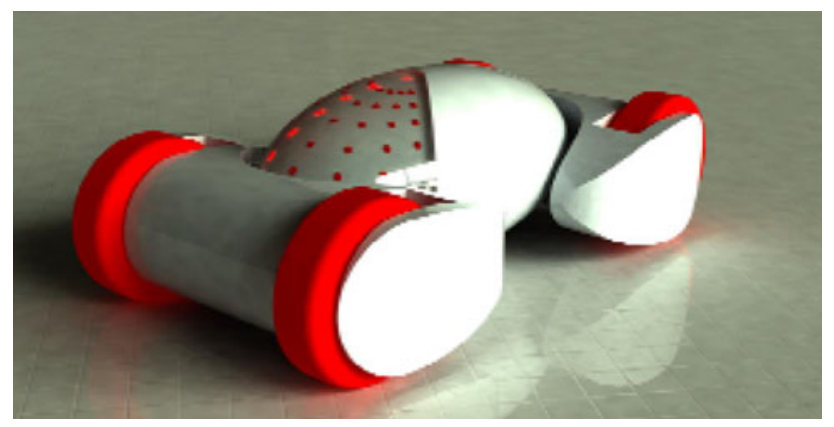

Fig. 1 A Battle Bot

allow the children to remotely control the bot. When leaning forward the robot moves forward, whereas leaning backwards will make the robot drive backwards. The amount of physical activity determines the speed of the robot. Turning the upper body will cause the robot to change direction. The glove is used to aim the robot's laser gun, which is indicated on the robot using LEDs. Aiming the glove will change the direction of the gun, and a button can be pressed to shoot the gun.

A small-scale user test was carried out $(N=12)$ to examine whether children understood how to control the tank and whether the movements for controlling the tank were appealing. Both girls and boys liked the global concept, but boys particularly liked the battle fantasy component of the design. They were quickly able to control the prototype and tried out the various ways of controlling the prototype. Overall, the children were enthusiastic about controlling the tank with their body movements. Children who did not control the tanks themselves enjoyed giving advice to the players.

\subsubsection{Design case 2: Feedball}

In the Feedball project, we intended to combine the essence of soccer with the rules of game design to create a new fun sport concept [8]. The Feedball allows children between 10 and 12 years of age to practice football skills in a playful manner (see Fig. 2).
The Feedball can be kicked, thrown and caught like a normal ball. Using a tilt sensor and an accelerometer, it senses acceleration and direction and calculates the precision of a pass. Based on this information, it provides visual feedback about the quality of the movement. The Feedball can be used by individuals to train personal skills, or in a group to stimulate competition and teamwork. Several games were designed to be played with the Feedball, for example the Five Pass Game (see Fig. 2). This game is simple and can be played anywhere with a varying number of players. Passing a ball around before scoring emphasizes the importance of team play.

We carried out an informal user test with 12 children and a football trainer to validate whether the children understood and enjoyed the games. Besides a number of issues concerning the implementation of the ball and the games, we found that children were much more active in sessions with the sensor-enhanced football than in the traditional training sessions.

\subsubsection{Lessons learned about motivating feedback}

The two design cases, where the objects provide feedback related to children's actions, show that receiving feedback can stimulate children to be physically active. The direct link between their body movement and the movement of the Battle Bots stimulates children to play and explore different kinds of movements using their fantasy or imitating other children. The more functional feedback of the Feedball motivated children to actively practice various skills. Finally, we found that onlookers also become involved by providing ideas to the children playing with the interactive objects.

\subsection{Open-ended play}

Our second design value is based on the idea that rather than providing concepts with concrete game goals and rules, providing local interaction opportunities with play objects may lead to interesting global game goals. Thus, the meaning of the objects and interactions only becomes
Fig. 2 The Feedball and a description of a Feedball game

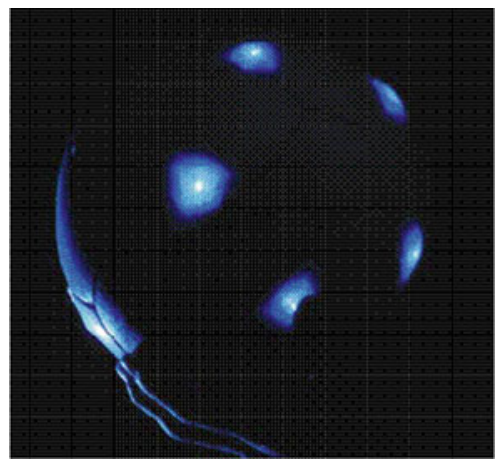

Five Pass Game

This game is played with two teams who need to score in the same goal. The Feedball counts the number of passes between players, by measuring the acceleration of the ball. After the first pass, the ball lights up a little bit; after five passes it is fully lit. Now both teams can use it to score a goal. The ball will stay lit for 10 seconds; if none of the players scored, the ball will turn off and five passes are needed to light it again. The team that scores the most goals is the winner. 
Fig. 3 The LEDtube prototype and children playing a game
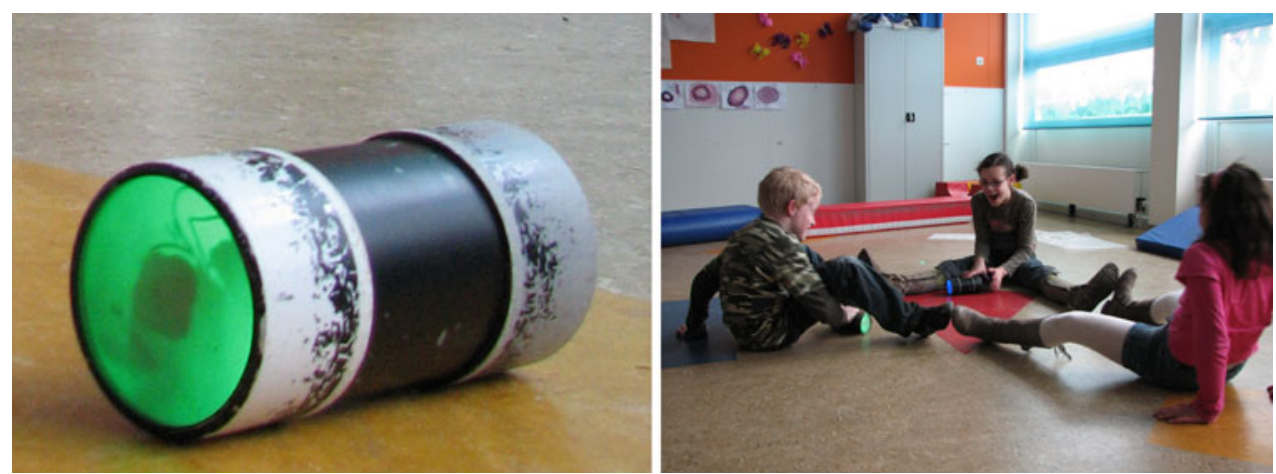

defined in way they are used. We call this open-ended play. This idea is inspired by theories about situated action [25, 29, 44] and about emergent behavior in decentralized systems [35]. Instead of designing for goal-directed behavior, as is assumed by, for example, Norman's action cycle [30], the situated actions model assumes that players do not structure their activity beforehand, but that activity grows as the interaction in the context of use occurs. People are opportunistic as they interact with the world. We assume that by providing local interaction opportunities as a support for situated actions global play patterns will develop [14]. Resnick [35] provides various examples from nature where local behavior leads to global patterns. For example, individual birds in a flock use only simple local rules related to nearby birds, which lead to organized flock patterns. Programs in his parallel programing environment StarLogo have shown that by giving objects or agents local rules overall patterns can occur in simulated environments (or microworlds). We translate this idea to players interacting with multiple objects in the real world, and assume that overall play patterns will emerge when players use objects with local interaction opportunities. The main difference with the work by Resnick is that in our case the total system does not only include (virtual) agents with predefined and fixed rules, but that it contains both interactive play objects with embedded rules and players that will determine their own behaviors which change over time.

Another reason why we think open-ended play is a promising design value is based on the analysis of how children play games. Even when children play games with official rules, they still create many rules specific to a particular play context. There is a large difference between the formal rules related to games and the real rules that are applied when children play games [18]. Based on various studies of how children play games, it is clear that they are capable of creating and adapting game rules and that this is an important aspect of their play behavior. We expect that creating concepts without overall game goals will stimulate players to use their creativity to develop their own game goals. Furthermore, we expect that it will also stimulate social interaction because players will have to negotiate and discuss their ideas about rules and games.

We will describe three design cases in which we developed our understanding of intelligent objects for open-ended play. All three cases also incorporate the assumption that play objects should provide motivating feedback to players' behavior (design value 1 ). The first concept, which had fairly limited interaction possibilities, was designed to explore whether players enjoy interacting with open-ended play objects. In the two subsequent cases we investigated our assumption that more complex games can be created if there are more (input and output) interaction opportunities to which children can assign meaning.

\subsubsection{Design case 3: LEDtube}

Our first exploration of open-ended play resulted in an interactive object that had very simple behavior, the LEDtube (in the concept was originally called the LEDball, e.g. in $[6,42])$. This prototype served as a proof of concept for open-ended play, rather than as a concept that would be further developed into a concrete product. The LEDtube is a cylinder emitting light at each end (see Fig. 3). Using motion sensors, the LEDtube reacts to children's behavior by changing the color of light (red, blue or green). Two variants of the LEDtube were created: one changes color when it is rolled; another when it is shaken.

We carried out a study with the LEDtube $(N=23)$ in which we explored the effects of simple open-ended, interactive play on social interaction, creativity, and fun. To this end, we compared a condition in which the LEDtubes were used in a pre-defined game and a condition in which they were used in an open-ended play session, in which the children were encouraged to come up with new games with their own goals and rules. Five groups of four children and one group of three children participated in the study. A within-subject design was used, and the order of the conditions was counter-balanced. After each session, they were asked to rate their opinion on several aspects, 
Fig. 4 ColorFlares and children trying to send the color of their ColorFlares
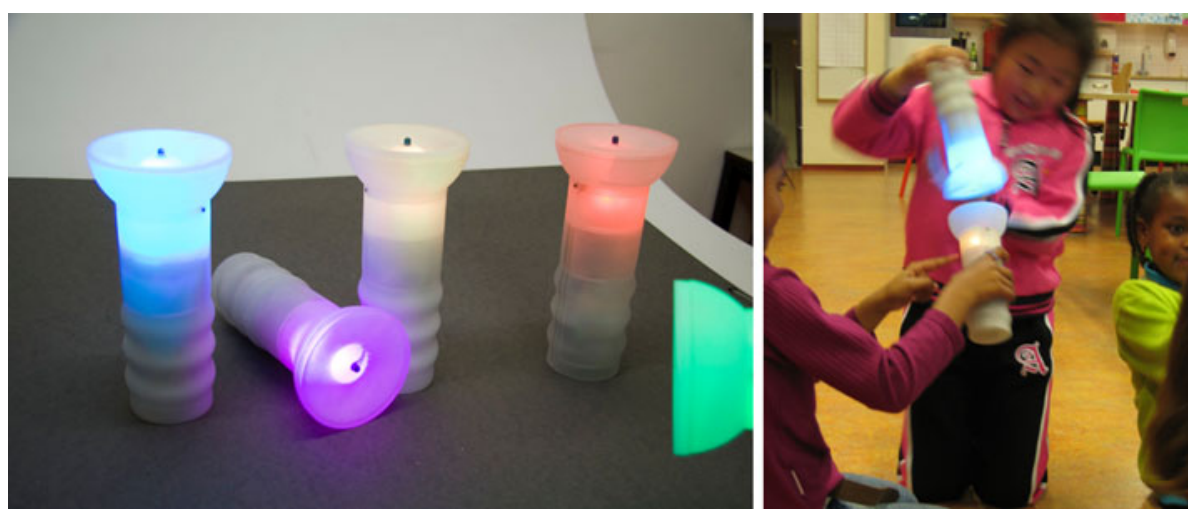

such as how much they had collaborated, whether they talked a lot during play, whether they liked playing with the object on a 5-point scale.

From this study we conclude that open-endedness is a promising concept for interactive play objects. We found that the children were able to create diverse games, with varying levels of difficulty. The children devised their own challenges, often in terms of physical challenges like running faster, rolling further, etc. The games that children played were mainly very simple games, e.g. rolling the LEDtubes to each other. Often the visual feedback was not used explicitly in the games that were played. Although no significant differences were found between open-ended play and predefined play in perceived amount of collaboration (Sign test, $N=10, k=5, p>0.05$ ) and talking (Sign test, $N=10, k=6, p>0.05$ ), the content of the communication was different in the two conditions. In the free-play condition verbal communication was mostly about which games the children would play, setting the rules of the games, and whether the rules were applied correctly or not, whereas in the game condition verbal communication mostly had an encouraging/motivating nature. The overall appreciation of playing with the prototypes was quite high: a median score of 5 (on a 5-point scale) for the free-play sessions and a median of 4 for the pre-set game sessions. Children rated playing in the openended play sessions significantly higher than in the game sessions (Sign test, $N=7, k=5, p<0.05$ ).

\subsubsection{Design case 4: ColorFlare}

The LEDtube study provided the first proof-of-principle of open-ended play. We then proceeded to design the ColorFlare, a concept based on the LEDtube, but providing more interaction possibilities and using more colors of light for feedback. In this way, we increased the number of states to which the children can allocate meaning and thus support more diverse games, which may increase the chance that children enjoy playing with it over time. When children roll the ColorFlare, it will change color and when they shake it, it will start to flash. When the objects are in flash mode, they can communicate with each other using infrared communication: when one ColorFlare is within the range of another one, it will transmit its color to the other ColorFlare (see Fig. 4).

The interaction possibilities of the ColorFlare and its open-ended nature provide ample opportunities for children to use their creativity. Furthermore, the ColorFlares' possibility to communicate with each other affords games that are played together, in which competition, collaboration, and communication play an important role.

A user study $(N=19)$ was carried out to explore player behavior and experiences when playing with the ColorFlares [9]. Six groups of children (5 groups of 3 and 1 of 4 children) were asked to play with the ColorFlares for about $30 \mathrm{~min}$, during which they were free to play the way they wanted. Video recordings were made to analyze play behavior in terms of the number and types of games that children created and the functionalities that were used in the games. After the play sessions the children filled in a (5-point) Likert-scale questionnaire [33] addressing aspects of immersion, positive affect, challenge, social interaction, creativity, and physical activity.

On average about six games were created per group, with a range from 3 to 12. Many games made use of the ColorFlare's interaction opportunities: combining the rolling and the shaking/sending functions. For example, a game in which children had to roll the ColorFlare to a specific color and then send their color to as many other ColorFlares as possible. Only in two out of the total of 38 games identified in this study the functionality of the ColorFlares was not used at all; in these games the children were just rolling the prototypes to each other, like we often observed with the LEDtube.

We categorized the games children played into six categories: assignment, tag, hide-and-seek, rolling, role-play, guessing, and a rest category. Most groups played games like tag, or hide-and-seek or made up small assignments for the group that could be won. Comparing the type of games played with the LEDtube and the ColorFlare, children 
came up with more diverse games using the ColorFlare. Apparently, the extended functionality of the ColorFlare provides more opportunities for games and rules. An example of how the use of the ColorFlare extends traditional games is that during a game of tag children can be tagged at a distance, and even by bouncing the ColorFlare signal of a mirror.

The observations about creativity are supported by data from the questionnaire. Overall, children indicated that they could use their imagination during play (average 3.8; SD 1.5). Also, children indicated that they were able to create various games using the ColorFlares (average 3.6; SD 1.7). Our observation that children did not adapt the rules during playing is supported by the fact that the statement 'I could create new rules while playing' got a lower score (average 2.8; SD 1.9).

\subsubsection{Design case 5: MultiModalMixer}

Design cases 1-4 all concern interactive play objects with light feedback as the only modality. With the Multimodal Mixer concept [17], we extended the 'game space' by providing multiple output modalities. The Multimodal Mixer is an extension to the ColorFlare (see Fig. 5). Its interaction possibilities are the same (rolling, shaking and sending), but instead of only providing light feedback, the Multimodal Mixer provides feedback in three different modalities. In addition to different colors of light, it provides sound (when it is shaken) and vibration (when it receives a signal from another Multimodal Mixer).

Since each modality has its own specific characteristics [26], we expect that the different types of output will trigger particular behavior of the players and eventually affect the type of games they create [17]. For example, objects that provide tactile feedback may trigger more secretive games than objects that emit light because of the invisible and mysterious character of the feedback. Offering multiple modalities may therefore not only allow for more but also for more diverse games.
A user test $(N=37)$ was carried out to explore the effect of multiple feedback modalities on children's creativity (in terms of the number and type of games) and their experience [17]. Ten groups of 3-4 children played with the Multimodal Mixers in a free play session of $30 \mathrm{~min}$. The user test had a between-subjects design: half of the groups used the multimodal version of the Multimodal Mixer, whereas the other groups used a unimodal version of the Multimodal Mixer, which has light as the only feedback modality. All sessions were recorded on video and after the test all children filled in a questionnaire. The data analysis was the same as in the ColorFlare study.

The children in the multimodal setting created only a few more games than those who used the unimodal version of the interactive prototype ( 43 vs. 39 , respectively). Every group was able to come up with multiple games (ranging from 4 to 13 games per session), and the children played nonstop for $30 \mathrm{~min}$. The use of color and infrared communication was used most frequently in both conditions. The flashing of the light (shaking) was never used in the unimodal setting, whereas sound (which has the same input modality) was used in multiple game variations in the multimodal condition. Sometimes the children made combinations of several different modalities. Occasionally children did not use any of the interaction possibilities in their games, e.g. when they used the toy standing upright on the floor. An interesting finding is that the children in the multimodal condition used a wider range of input modalities, such as using the shaking functionality and combining multiple output modalities, in their games than the players in the unimodal condition. Apparently, offering various types of feedback made it easier to implement different functionalities in the game.

The most popular type of game in the unimodal condition was the game of Tag ( 13 out of 39 games), while in the multimodal condition games in the categories assignment and hide and seek were played most often (16 and 10 out of 43 games, respectively). The differences can be explained in terms of feedback modalities; for example, in the
Fig. 5 The Multimodal Mixer and children playing with the prototypes
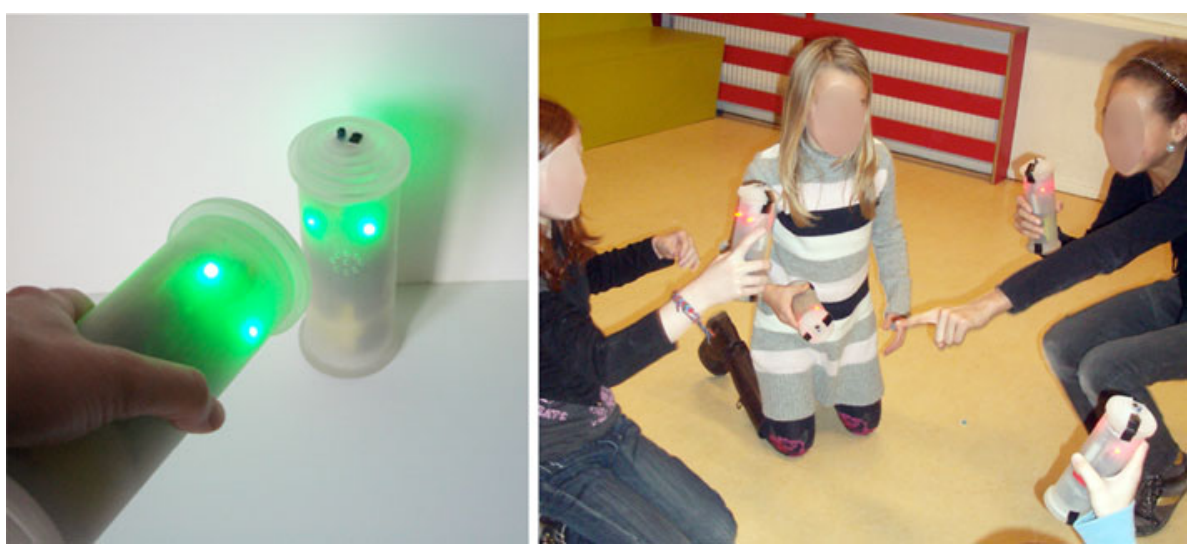
multimodal setting there are more diverse types of output modalities that can serve as inspiration for an Assignment. Tagging is much easier with a visible signal than an invisible one: it is clear for every single player who is tagged and who is not.

The findings about the children's creativity from our observations are supported by the results of the questionnaire. For example, children in both conditions were quite positive about whether they could use their fantasy while playing (unimodal average 4.05, SD 1.27; multimodal average 3.94 , SD 1.21). The children also indicated that they had many ideas for new games (unimodal average 3.47, SD 1.35; multimodal average 3.29, SD 1.31) and that they would be able to create new games when they would have another opportunity to play with the multimodal mixer (unimodal average 3.89, SD 1.49; multimodal average 4.00, SD 0.97).

\subsection{Lessons learned about open-ended play}

Overall, players enjoy creating their own games. Players allocate various meanings to the interaction opportunities, such as the color of an object determining the player's role in a game, or using the sending functionality to play searching games. They create multiple games during a session and often add new rules as they play the game. In terms of social interaction, players negotiate game goals and rules during play sessions. Moreover, many children played games in groups, ranging from rolling the objects to each other to playing hide-and-seek. The social interaction during play strongly depends on the interaction opportunities that are offered and their characteristics: e.g. when providing objects that can communicate, players are stimulated to create games with more social components.

Providing different and more interaction opportunities leads to more diverse and more complex games in which the interaction modalities play an actual role. Since interaction opportunities have specific characteristics, such as being persistent or not, they influence the kind of games that are created. However, providing too many options can be overwhelming at the start. Furthermore, it is important to find a balance between offering an abstract shape and at the same time providing clear interaction possibilities.

\subsection{Social player interaction patterns}

Our third design value is related to the idea that object characteristics may influence the way players interact when playing the games and thus affect social interaction. The theories that have inspired us most regarding social interaction are theories about social play by Parten [31] and Broadhead [11]. Parten [31] defined the degree of play participation in six sequential social participation categories: unoccupied behavior, solitary play, onlooker behavior, parallel play, associative play, and cooperative play. The theory developed by Broadhead describes the various social play behaviors in more detail. She created a methodology called the Social Play Continuum [11], in which social play behavior is measured by the level of reciprocity in language and action. The Continuum describes four social domains: associative play, social play, highly social play, and cooperative play.

Social interaction can be provoked by a game, which is played by multiple players. The type of relation between the players can influence the type of social interaction that will occur. The structure of interaction between a player, the game (objects) and other players is a so-called player interaction pattern [16]. Figure 6 shows various player interaction patterns in the case of one central game system or object. The figure shows that the patterns are related to - among other things - the number of players, whether the game is collaborative or competitive and whether the players play against other players or against the game system.

Choosing various object characteristics - such as interaction opportunities, shape, and intended use-can influence the affordances of an object for a particular player interaction pattern. The shape of an object can influence
Fig. 6 Player interaction patterns (after [16])

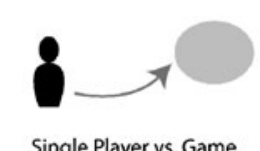

Single Player vs. Game

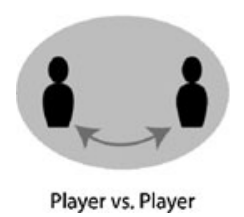

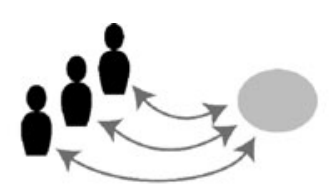

Multiple Individual Players vs. Game

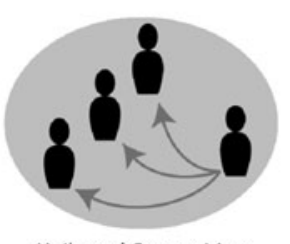

Unilateral Competition
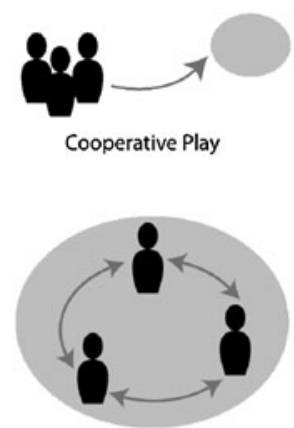

Multilateral Competition

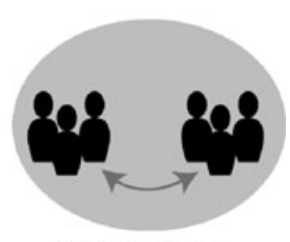

Team Competition 
whether players are likely to keep the object to themselves or share it with others. Some shapes, such as a ball are more easily shared, while others, such as bracelets, are more likely to be kept to oneself. Another way to influence social interaction can be when play objects respond to each other, and thus trigger players to discover or use this communication in their games.

Three design cases are described in terms of how design characteristics of play objects influence social interaction patterns. Design case 6 compares personal with shared objects. This design case also incorporates design value 1 of providing motivating feedback, but does not include open-ended play (design value 2). A further discussion of design cases 4 and 5, which incorporate all three design values, examines how communicating objects influence social interaction between players.

\subsubsection{Design case 6: Swinxsbee}

The Swinxsbee case is an illustration of how players' interaction patterns were used as an inspiration source to design for more social interaction [22]. Swinxs is a commercially available game console for children aged 4-12 [43]. It facilitates active games that can be played indoor or outdoor. Swinxs comes with colored bracelets containing an RFID-tag, which Swinxs uses to recognize players. An analysis of Swinxs' games has shown that current Swinxs games do not include player interaction patterns stimulating collaborative or team play. Therefore, our aim was to design an object that supports collaborative or team play, which can lead to a high degree of social interaction.

The Swinxsbee is a Frisbee that contains an RFID-tag (Fig. 7) that can be detected by the RFID reader embedded in the game console [22]. The fundamental difference between Swinxsbee and the existing bracelets is that the bracelets are personal objects and Swinxsbee is a shared object.

A study was carried out $(N=16)$, with children playing in groups of four to examine our hypothesis that playing with a shared object enhances social interaction as compared to playing with a personal object [22]. The within-subject test was carried out with two conditions; one with the Swinxsbee used in team competition games and one with the original bracelets used in multilateral competition games (see Fig. 6). In each of the two conditions two games were played. We analyzed player experience with a questionnaire addressing topics like positive affect, physical activity, and social interaction. Moreover, we made a detailed analysis of players' social behavior on the basis of video material of the play sessions. Because adequate coding schemes for our purpose were lacking, we created an observation scheme ourselves, based on the Social Play Continuum, the Play Observation Scale and the Outdoor Play Observation Scheme [3, 11, 38]. The scheme describes four levels of social interaction: low, medium, high, and rich, ranging from solitary play to cooperative play. For a more detailed description of the categories, see [22]. The coder scored the play behavior of a specific child every $10 \mathrm{~s}$. This was done for each child in a group. An overall social interaction score was then calculated based on an average of the scores for social interaction levels 1 (low) to 4 (high).

The results show that children playing with the Swinxsbee have a significantly higher social interaction level (average $=2.9, \mathrm{SD}=0.01$ ) than children playing with the bracelets (average $=2.2, \mathrm{SD}=0.03)(n=16, p<$ $0.001)$. The average scores for social interaction for the two bracelet games are very similar. Thus, we found that the ability to share the use of the Swinxsbee leads to a high level of social behavior. The players carefully looked at each other to defend the attackers, or to make sure the defenders do not intercept the Swinxsbee. The children watched each other carefully and communicated both verbally and non-verbally. The fact that one of the Swinxsbee games required a large amount of physical exercise had a big influence on the social interaction; in the end, the children were too exhausted to communicate and keep focus on each other and the game. One of the Swinxs bracelet games also stimulated social interaction. The silly music played during the game provoked funny dance
Fig. 7 The Swinxsbee prototype and children playing a game with the Swinxsbee
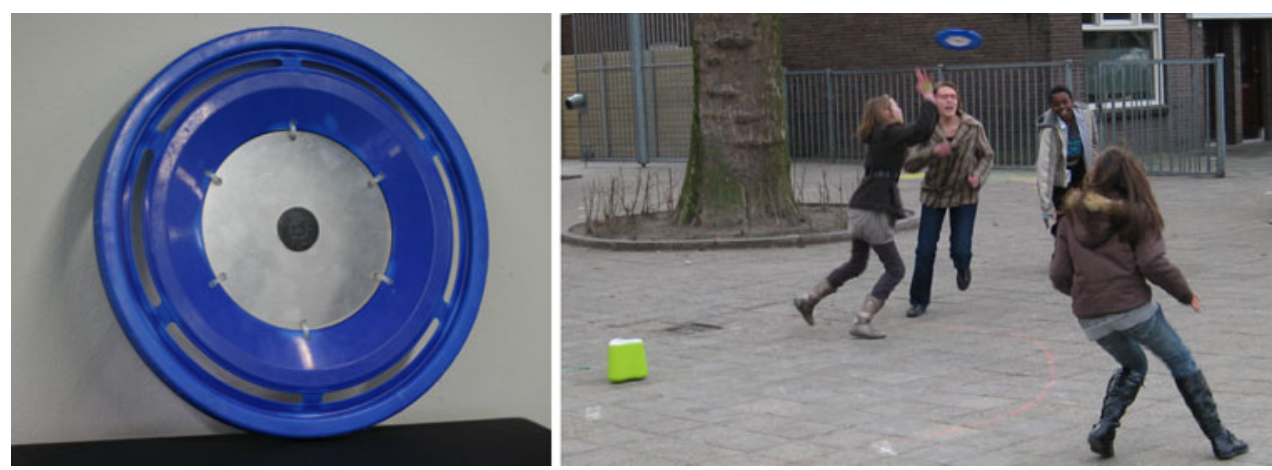
moves. This creativity and humor in the game regularly led to a high level of social interaction. The questionnaire results showed that the children perceived more social interaction during Swinxsbee games than during bracelet games (Wilcoxon signed ranks test, $p<0.05$ ). We conclude that collaboration within teams positively influences the level of social interaction in a game. A shared object like Swinxsbee is able to provoke cooperation, but should be supported by the right game objectives and rules.

\subsubsection{Design cases 4 (ColorFlare) and 5 (MultiModal Mixer) revisited}

We will now describe some of the findings of children playing with the ColorFlare and the MultiModal Mixer in relation to the design value of social interaction patterns.

In all three open-ended play concepts children mostly played games in groups with different social interaction patterns: they create player versus player tournament like games, team competition games with for example one team of cops and another team of robbers, and role playing games that include cooperative play. In the ColorFlare and MultimodalMixer case, the fact that the play objects can send and receive information stimulated the children to explore games that use this functionality leading to games with a social interaction component.

Furthermore, the open-ended play concepts stimulate social interaction patterns in the sense that children jointly create game goals and rules, sometime explicitly and sometimes more implicitly. They often respond to and copy behavior of other children in their group. For example, when one child blocked the infrared receiver to block being 'hit' another child also started using this strategy during a game. Furthermore, during the play session they often change or add game rules, which might be adopted, adjusted or ignored.

\subsubsection{Lessons learned about social interaction patterns}

In the Swinxs design case we found that the use of shared objects in collaborative games stimulates social interaction in comparison with playing with a personal object. The goals and the rules of a game can stimulate social interaction, e.g. in games where players have to collaborate to reach the game goal. However, social interaction may be hindered when the intensity of the games in terms of physical activity is too high. In the same way, open-endedness also provides opportunities for social interaction during play, because it requires players to negotiate about game goals and rules. Finally, the specific properties of an open-ended play concept (e.g. the possibility to send and receive information) can elicit game goals and rules that require children to play together, instead of playing more in parallel.

\section{Conclusion}

In various projects we have created interactive play objects that stimulate social interaction and physical play. We have described three design values and illustrated how they can be applied in various contexts of use. While most concepts have only been evaluated in a fairly informal manner, this has been compensated by verification of general design assumptions in multiple contexts of use. The contribution of our work lies in the application of the design values in multiple design projects, by exploring the influence of design variations and especially in the ideas behind designing open-ended play solutions.

Some cases were designed focusing on only one design value, while others have included all three. If combined in a coherent manner the three values can be integrated into one concept, although in some instances they might lead to unintended consequences, such as the example where the amount of physical activity required was so high that it had a negative effect on social interaction. As always in design, proper combinations of design considerations have to be checked and adjusted in an iterative process.

Furthermore, the design cases have strengthened our view that interactive play objects can extend traditional play opportunities by providing opportunities for children to allocate meaning to diverse interaction properties, such as input actions, and output properties of the play objects. For example, sending tactile output to another player's objects can extend the sense of secrecy and surprise in playing hide and seek.

We still have a number of research issues to address. For example, most studies to date, both our own and those by others, have focused on initial use. It is unclear how players will interact with open-ended play objects over a longer a period of time. Will the interactive play concepts stand the test of time? Some of our future plans are to verify how players interact with the open-ended objects during prolonged use. Furthermore, we intend to further develop the coding scheme to describe social play. This will allow us to examine in more detail how design variations influence social interaction between players.

In summary, we have shown that providing feedback to the players' physical activity and allowing them to create their own games may lead to concepts that are fun to use and stimulate both social interaction and physical activity. We have already explored various implementations of the overall design values and will continue to investigate further variations to expand our knowledge.

Acknowledgments We would like to thank the students and designers who created the various concepts described in this paper: Werner Bastianen, Connie Golsteijn, Bart Neefs, Jeroen Witjes, Kerem Zaglül (Battle Bot), Jop Japenga, Dripta Roy, Ralph Kooijman, Stijn Weterings, Jeroen Verhoeven (Feedball), Jos Verbeek 
(ColorFlare), Eva Hopma (MultiModal Mixer), and Martijn Jansen (Swinxsbee). We are also grateful to Bas Groenendaal, Rik Wesselink (Ledtube), Harm van Essen and Mark de Graaf for their contributions and inspiration.

Open Access This article is distributed under the terms of the Creative Commons Attribution Noncommercial License which permits any noncommercial use, distribution, and reproduction in any medium, provided the original author(s) and source are credited.

\section{References}

1. Acuff DS, Reiher RH (1997) What kids buy and why: the psychology of marketing to kids. Free Press

2. Al Mahmud A, Mubin O, Octavia JR, Shahid S, Yeo L, Markopoulos P, and Martens JB (2007) aMAZEd: designing an affective social game for children. In: Proceedings of the 6th international conference on interaction design and children (IDC'07)

3. Bakker S, Markopoulos P, de Kort Y (2008) OPOS: an observation scheme for evaluating head-up play. In: Proceedings of the 5th Nordic conference on human-computer interaction (NordiCHI)

4. Bandura A (1997) Self-efficacy: the exercise of control. Freeman, New York

5. Bekker M, van den Hoven E, Peters P, Klein Hemmink B (2007) Stimulating children's physical play through interactive games: two exploratory case studies. In: Proceedings of interaction design and children (IDC'07), pp 163-164

6. Bekker T, Sturm J, Wesselink R, Groenendaal B, and Eggen B (2008) Interactive play objects and the effects of open-ended play on social interaction and fun. In: Proceedings of international conference on advances in computer entertainment technologies (ACE), pp 389-392

7. Bekker T, Sturm J, Barakova E (2008) Designing for social interaction through physical play, In: Extended abstracts of conference on fun and games 2008, pp 62-67

8. Bekker T, Eggen B (2008) Designing for children's physical play. In: CHI 08 extended abstracts on human factors in computing systems, pp 2871-2876

9. Bekker T, Sturm J. (2009) Stimulating social and physical activity through open-ended play. In: Proceedings of interaction design and children, IDC 2009, Como, Italy, pp 309-311

10. Benford S, Crabtree A, Flintham M, Drozd A, Anastasi R, Paxton M, Tandavanitj N, Adams M, Row-Farr J (2006) Can you see me now? ACM Trans Comput Hum Interact 13(1):100-133

11. Broadhead P (2004) Early years play and learning: developing social skills and cooperation. RoutledgeFalmer, London

12. Cheok AD, Lee SP, Kodagoda S, Tat KE, Thang LN (2005) A social and physical inter-generational computer game for the elderly and children: age invaders. In: Proceedings of the 9th IEEE international symposium on wearable computers (ISWC '05), pp 202-203

13. DHHS (US Department of Health and Human Services) (2008) 2008 physical activity guidelines for Americans

14. van Essen H, Rijnbout P, de Graaf M (2009) A design approach to decentralized interactive environments. In: Nijholt A, Reidsma $\mathrm{D}$, Hondrop $\mathrm{H}$ (eds) Intelligent technologies for interactive entertainment, LNICST, vol 9. Springer, Berlin, pp 56-67

15. Fogg BJ (2003) Persuasive technology: using computers to change what we think and do. Morgan Kaufmann, San Francisco

16. Fullerton T, Swain C, Hoffman S (2004) Game design workshop. CMP Books, San Francisco

17. Hopma E, Sturm J, Bekker T (2009) Interactive play objects: the influence of multimodal output on open-ended play. In:
Proceedings 3rd international conference on intelligent technologies for interactive entertainment (Intetain'09), Amsterdam, The Netherlands, pp 78-89

18. Hughes LA (1995) Children's gaming. In: Sutton-Smith B, Mechling J, Johnson T, McMahon F (eds) Children's folklore: a sourcebook. Garland, New York, pp 93-119

19. Humphrey JH (2003) Child development through sports. Haworth Press, New York

20. IJsselsteijn W, Kort Y de, Midden C, Eggen B, van den Hoven E (2006) Persuasive technology for human well-being: setting the scene. In: proceedings of PERSUASIVE 2006, pp 1-5

21. Ishii H, Wisneski C, Orbanes J, Chun B, Paradiso J (1999) PingPongPlus: design of an athletic-tangible interface for computersupported cooperative play. In: Proceedings of CHI '99, pp 394-401

22. Jansen M, Bekker T (2009) The influence of personal and shared interactive play objects on social behaviour. In: Proceedings 3rd international conference on intelligent technologies for interactive entertainment (Intetain'09), Amsterdam, The Netherlands, pp 90-101

23. Kemper HGC, Ooijendijk WTM, Stiggelbout M (2000) Consensus over de Nederlandse Norm Gezond Bewegen. TSG 78:180-183

24. Koplan JP, Liverman CT, Kraak VI (2005) Preventing childhood obesity: health in the balance. The National Academic Press, Washington, DC

25. Lave J (1988) Cognition in practice. Cambridge University Press, Cambridge

26. Lemmelä S (2008) Selecting optimal modalities for multimodal interaction in mobile and pervasive environments. In: Proceedings of IMUx (improved mobile user experience) workshop, Pervasive 2008

27. Magerkurth C, Cheok AD, Mandryk RL, Nilsen T (2005) Pervasive games: bringing computer entertainment back to the real world. Comput Entertain 3(3):1-19

28. Mueller F, Stevens G, Thorogood A, O'Brien S, Wulf V (2006) Sports over a Distance. J Pers Ubiquitous Comput 11(8):633-645

29. Nardi B (1997) Studying context: a comparison of activity theory, situated action models and distributed cognition. In: Nardi B (ed) Context and consciousness: activity theory and human computer interaction. MIT Press, Cambridge, pp 35-52

30. Norman D (1990) The design of everyday things. Basic Books, New York

31. Parten MB (1932) Social participation among preschool children. J Abnorm Soc Psychol

32. Payne VG, Isaacs LD (2002) Human motor development: a lifespan approach. McGraw-Hill, London

33. Poels K, IJsselsteijn WA, de Kort YAW (2008) Development of the kids game experience questionnaire: a self report instrument to assess digital game experiences in children. Poster Presentation at the Meaningful Play conference, Michigan

34. Renders CM, Seidell JC, van Mechelen W, Hirasing RA (2003) Overgewicht bij kinderen en adolescenten (Obesity in children and adolescents). Elsevier Gezondheidzorg, Maarssen

35. Resnick M (1997) Turtles, termites and traffic jams explorations in massively parallel microworlds. MIT Press, Cambridge

36. Rogers Y, Price S (2004) Extending and augmenting scientific enquiry through pervasive learning environments: children. Youth Environ 14(2):67-83

37. Rogers Y, Muller H (2006) A framework for designing sensorbased interactions to promote exploration and reflection in play. Int J Hum Comput Stud 64(1):1-14

38. Rubin KH (2008) The play observation scale (POS). The Center for Children, Relationships, and Culture of the University of Maryland

39. Soute I, Markopoulos P (2007) Head up games: The games of the future will look more like the games of the past. In: Proceedings of INTERACT 2007, pp 404-407 
40. Stienstra J, Hopma, Bekker M (2006) 'Move it'-a persuasive game for 11-year old children to increase awareness about a healthy balance between eating and exercising. In: Adjunct proceedings of persuasive 06 , pp 21-25

41. Sturm J, Bekker T, Groenendaal B, Wesselink R, Eggen B (2008) Key issues for the successful design of an intelligent interactive playground. In: Proceedings of interaction design and children (IDC'08)

42. Sturm J, Bekker T, Eggen B (2008) Playful interactions: social interaction through open-ended physical play. In: Proceedings of 1st workshop on design for social interaction through physical play, pp 63-70

43. Swinxs website. http://www.swinxs.com. Accessed 29 May 2009

44. Suchman L (1987) Plans and situated actions. Cambridge University Press, Cambridge

45. Weinberg RS, Gould D (2003) Foundations of sport and exercise psychology. Human Kinetics 